\title{
Energy efficiency subsidies with price-quality discrimination
}

\author{
Marie-Laure Nauleau ${ }^{\mathrm{a}, \mathrm{b}}$, Louis-Gaëtan Giraudet ${ }^{\mathrm{a}, \mathrm{c}, *}$, Philippe Quirion ${ }^{\mathrm{a}, \mathrm{d}}$ \\ a Centre international de recherche sur l'environnement et le développement (CIRED), France \\ ${ }^{\mathrm{b}}$ Agence de l'environnement et de la maîtrise de l'énergie (ADEME), France \\ ${ }^{c}$ Ecole des Ponts ParisTech, France \\ d Centre national de la recherche scientifique (CNRS), France
}

\section{A R T I C L E I N F O}

Available online 4 September 2015

\section{JEL classification:}

D42

D62

$\mathrm{H} 23$

Q48

Q58

\section{Keywords:}

Energy efficiency subsidies

Price-quality discrimination

Ad valorem incentive

Per-quality incentive

Energy efficiency gap

Energy-use externalities

\begin{abstract}
A B S T R A C T
We compare various designs of energy efficiency subsidies in a market subject to both energy-use externalities and price-quality discrimination by a monopolist. We find that differentiated subsidies can establish the social optimum. Unlike per-quality regimes, ad valorem regimes generate downstream interferences: Subsidising of the high-end good leads the monopolist to reduce the quality of the low-end good. For this reason, ad valorem differentiated rates should always decrease with energy efficiency, a result seemingly at odds with actual practice. In contrast, with per-quality differentiated subsidies, the rates can increase if the externality is large enough relative to the market share of "low" type consumers. Contrary to differentiated subsidies, what we shall call single-instrument subsidies only achieve second-best outcomes. A uniform ad valorem subsidy should have a rate higher than that needed to specifically internalise energy-use externalities. Lastly, if, as is often observed in practice, only the high-end good is to be incentivised, a per-quality regime should be preferred to an ad valorem one. An ad valorem tax on the high-end good may even be preferred to an ad valorem subsidy if the externality is small enough and low-end consumers dominate the market.
\end{abstract}

C 2015 Elsevier B.V. All rights reserved.

\section{Introduction}

Energy efficiency has become a popular theme in the policy arena. This enthusiasm is sustained by engineering studies claiming that energy efficiency is the most cost-effective way to save energy, hence internalising the multiple externalities associated with energy use. ${ }^{1}$ Such externalities include carbon dioxide emissions at the source of the climate change problem, local pollution, risks related to nuclear safety and domestic concerns about the security of the energy supply. They encourage the implementation of various types of energy efficiency policies around the world. ${ }^{2}$

Within the panoply of energy efficiency policies, subsidies are probably the most widespread instrument. Energy efficiency subsidies come in a variety of forms. In the US, under the State Energy Efficient Appliance Rebate Program (SEEARP), States used Federal funds in 20092010 to subsidise efficient refrigerators, dishwashers and washing machines (Houde and Aldy, 2014). The rebates were on average 12-15\% of sale prices. While most states offered fixed rebate amounts, Florida, Illinois, North Carolina, and Oregon offered ad valorem rebates. In China, a one-year subsidy programme for energy-efficient home

\footnotetext{
* Corresponding author at: CIRED, 45 bis avenue de la belle Gabrielle, F-94736 Nogentsur-Marne Cedex, France. Tel.: + 33143947362.

E-mail address: giraudet@centre-cired.fr (L.-G. Giraudet).

${ }^{1}$ For instance McKinsey \& Co. (2009) to quote only that with the greatest impact.

2 For the European Union alone, 550 energy efficiency policies are referenced in the MURE database (http://www.measures-odyssee-mure.eu/).
}

appliances was implemented in 2012-2013. The programme consisted of offering cash rebates ranging from about 100 to 400 RMB Yuan (16 to 64 US dollars) per appliance (Yao et al., 2014). In France, improvements to building energy efficiency have been eligible for ad valorem tax credits since 2005 (Nauleau, 2014). The subsidies, whose rates initially increased in proportion to the gains in energy efficiency (e.g. $15 \%$ of the price of low-temperature boilers and $25 \%$ of the price of more efficient condensing boilers), are now restricted to the most efficient options. Meanwhile, since 2014, all energy efficient options have been eligible for a uniform value-added tax reduction.

In parallel to the importance of subsidies, another regularlyobserved characteristic of energy efficiency policies is the high concentration of the markets in which they are applied. In the US, Fischer (2005) documents high concentration levels in appliance manufacturing, as measured by Herfindahl-Hirschman indexes (HHI) and the market shares of the top four firms, which systematically exceed $50 \%$. In France, $\mathrm{HHI}$ indexes are also substantially higher in the appliance and energy retrofit industries than in other industries (Carbonnier, 2008). The French Anti-trust authority has pointed to high levels of concentration in the heating, air conditioning and hot water industries, both at the manufacturing and retail levels, raising suspicion of collusive practices (Conseil de la concurrence, 2006). ${ }^{3}$

\footnotetext{
3 The five largest firms have a 59\% market share in floor-standing boilers, the three largest firms have an $80 \%$ market share in wall-mounted boilers and the four largest firms have a $90 \%$ market share in electric heating systems.
} 
Imperfect competition as described above is conducive to pricequality discrimination. The problem, first studied by Mussa and Rosen (1978) for a monopoly and revisited by Cremer and Thisse (1994) for an oligopoly, can be explained as follows. A dominant firm faced with consumers having heterogeneous tastes for quality can choose to restrict the provision of quality at the bottom end of the product range while at the same time increasing the price of high-end products. As shown by Fischer (2005), this general economic problem can provide a supply-side explanation as to why energy efficiency levels are too low in the economy, a phenomenon known as the energy efficiency gap (Jaffe and Stavins, 1994). ${ }^{4}$ More recently, Houde (2013) and Spurlock (2013) in the US and Cohen et al. (2015) in the UK found empirical evidence that appliance industries do respond to economic and regulatory signals in a manner that is consistent with price-quality discrimination.

Despite the practical relevance of the issue, little is known about the properties of energy efficiency subsidies in a context of imperfect competition. ${ }^{5}$ Most of the discussions about the interaction between environmental policy and price-quality discrimination have focused on quality standards, pollution charges, and combinations thereof (Fischer, 2005, 2010; Plourde and Bardis, 1999). While some authors have considered tax/subsidy incentives (Bansal, 2008; Lombardini-Riipinen, 2005), attention has remained confined to single ad valorem instruments. As illustrated above, energy efficiency subsidies take a wider variety of forms in practice, with at least two unexplored consequences. First, according to Tinbergen's rule (Tinbergen, 1952), jointly addressing energy-use externalities and imperfect competition requires two instruments. Therefore, what we shall call single-instrument subsidies can only generate second-best outcomes unless they are combined with pollution charges, a much less common instrument. In contrast, differentiated subsidies, while overlooked in the literature, offer more flexibility to address both market failures. ${ }^{6}$ Second, ad valorem subsidies have not yet been compared to specific subsidies related to the quality of the good. Such a comparison could reveal interesting effects, as suggested by the taxation literature (Keen, 1998).

Against this background, we examine the following questions: What are the normative and positive aspects of energy efficiency subsidies in a market subject to both energy-use externalities and price-quality discrimination? How do differentiated subsidy rates compare to uniform rates? How do ad valorem rates compare to per-quality rates? We provide some answers using Fischer (2005)'s model featuring a multiproduct monopolist and two consumer types with fixed market shares. We extend the model by explicitly taking into account energy-use externalities and accommodating energy efficiency subsidies.

We find that in an economy subject to both energy-use externalities and price-quality discrimination, differentiated subsidies can generate the first-best solution. Unlike per-quality regimes, ad valorem regimes generate downstream interferences: subsidising of the high-end good leads the monopolist to cut the quality of the low-end good. For this reason, ad valorem differentiated rates should always decrease with energy efficiency, a result seemingly at odds with actual practice. In contrast,

\footnotetext{
${ }^{4}$ Supply-side explanations for the energy efficiency gap have been little studied. The existing literature on the topic tends to focus more on demand-side explanations. For comprehensive reviews, see Sorrell (2004), Gillingham et al. (2009) and Allcott and Greenstone (2012).

5 The existing literature on energy efficiency subsidies is mostly empirical and concerned with estimating the effectiveness of, and inframarginal participation in, subsidy programmes (Boomhower and Davis, 2014; Grösche and Vance, 2009; Hassett and Metcalf, 1995; Houde and Aldy, 2014; Nauleau, 2014).

${ }^{6}$ Energy efficiency subsidies can be used to address either market failure in isolation. Subsidies are a conceptually valid tool to address output contraction due to market power. Yet such an intervention increases the profits of dominant firms and thus faces political hurdles. Moreover, it is only a substitute for anti-trust regulation. Subsidies can also directly address energy-use externalities. However, they may generate a rebound effect, thus saving energy less cost-effectively than taxation of externalities (Giraudet and Quirion, 2008). Note that subsidies can also be used to internalise technology spillovers, a market failure not considered in the model but discussed in Section 5 .
}

with per-quality differentiated subsidies, the rates can increase if the externality is large enough relative to the market share of "low" type consumers. Contrary to differentiated subsidies, single-instrument subsidies only achieve second-best outcomes. A uniform ad valorem subsidy should have a rate higher than that needed to specifically internalise energy-use externalities. Lastly, if, as is often observed in practice, only the high-end good is to be incentivised, a per-quality regime is to be preferred to an ad valorem one. An ad valorem tax on the high-end good may even be preferred to an ad valorem subsidy if the externality is small enough and low-end consumers dominate the market. In the Appendices, we use the model to provide new results on energy taxes and minimum energy efficiency standards. We find that a second-best energy tax should be set above the marginal external cost. A secondbest minimum quality standard may be set at the high-end of the product range if consumers are not too dissimilar, otherwise it should only target the low-end good.

The paper is organized as follows. Section 2 introduces the model and the market environments considered. Section 3 examines firstbest, differentiated subsidies. Section 4 examines second-best, singleinstrument subsidies. The results are discussed in Section 5. Section 6 concludes.

\section{Model}

Model notations are outlined in Table 1, equilibrium notations are outlined in Table 2 and illustrative equilibrium outcomes are summarized in Fig. 1.

\subsection{Consumer demand for energy efficiency}

We build on Fischer (2005)'s model and extend it to account for energy-use externalities and energy efficiency subsidies. Consumers purchase goods which, combined with energy, provide energy services such as light and heat. The energy-related goods considered can be appliances, light bulbs, heating systems, improvements to building envelopes (wall insulation, double glazing), vehicles, etc. They are characterized by their energy intensity $\phi_{j}>0$, bounded from above by $\Phi$, the energy intensity that would be offered if energy were costless. Energy intensity is the energy input per unit of energy service, hence the inverse of energy efficiency.

Energy efficiency is the only attribute of quality in the model. That is, quality is negatively correlated with energy intensity. We ignore ancillary attributes of the goods, such as capacity of appliances, aesthetics for light bulbs or safety for cars. This assumption is relevant to most choices within a capacity segment, e.g. a standard boiler versus a more efficient one of the same size, or a standard car versus a hybrid car with similar characteristics. It is less relevant to choices between capacity segments, e.g. a large boiler or car versus a smaller option with similar energy requirements per unit of capacity. ${ }^{7}$

We consider two levels of energy efficiency, high $(h)$ and low $(l)$, with corresponding energy intensities $0<\phi_{h}<\phi_{l}<\Phi$. For consumers $i$, the net surplus of purchasing and using good $j$ is

$C S_{i j} \equiv \beta_{i}\left(v-g \phi_{j}\right)-p_{j}$

$v>0$ is the annual gross utility of the energy service. It is produced with a combination of energy, purchased at a constant price $g>0$, and the durable good $j$, purchased at price $p_{j}>0$.

We assume heterogeneity across the population in the valuation of energy services. This is reflected by parameter $\beta_{i}$, the cumulative discount factor for the net utility flow over the lifetime of the good.

\footnotetext{
7 Plourde and Bardis (1999) study the opposite model in which quality is positively correlated with energy intensity, assuming that the safety attribute associated with larger cars is the main driver of choice. Unsurprisingly, they find opposite results to those of Fischer (2005).
} 
Table 1

Model notations.

\begin{tabular}{|c|c|c|}
\hline Variable & Definition & Illustrative unit \\
\hline$p_{h}, p_{l}$ & Price of durable goods & $€$ per durable good \\
\hline$v$ & Gross utility of energy service & $\begin{array}{l}€ \text { per unit of energy } \\
\text { service }\end{array}$ \\
\hline$\Phi, \phi_{h}, \phi_{l}$ & $\begin{array}{l}\text { Energy intensity (inverse of } \\
\text { energy efficiency) }\end{array}$ & $\begin{array}{l}\text { kWh per unit of } \\
\text { energy service }\end{array}$ \\
\hline$g$ & Energy price & $€$ per kWh \\
\hline$\gamma$ & External cost & $€$ per kWh \\
\hline$\beta_{h}, \beta_{l}$ & $\begin{array}{l}\text { Flow of energy service, discounted } \\
\text { over the lifetime of the durable good }\end{array}$ & Discounted years \\
\hline$n_{h}, n_{l}$ & $\begin{array}{l}\text { Proportion of consumers of each } \\
\text { type }\left(n_{h}+n_{l}=1\right)\end{array}$ & Percentage \\
\hline
\end{tabular}

Heterogeneity stems from either preferences or financial constraints. It is materialised by differences between consumers in their willingness to invest in energy efficiency and their frequency of utilisation of the goods after investment. For instance, a homeowner sensitive to the cold will be likely to upgrade his or her heating system and set the thermostat at a high temperature. Both margins are in fact identified as $\beta_{i}{ }^{8}$ For simplicity, we assume that consumers are of two types, high $(h)$ and low $(l)$, with $\beta_{h}>\beta_{l}$.

The two types of consumers cover the market in fixed proportions $n_{h}$ and $n_{l}$, with $n_{h}+n_{l}=1$. Through this assumption, we confine our attention to the intensive margin of investment. Therefore, our model is more relevant to capital maintenance investment (e.g. replacement of broken appliances or light bulbs) than to capital enhancement investment (e.g. improvements to the building envelope).

\subsection{The firm}

Energy efficiency is supplied at a convex increasing cost. In other words, the cost of energy intensity $c\left(\phi_{j}\right)$ decreases: $c^{\prime}<0$ and $c^{\prime \prime}>0$.

We assume that the firm is a monopolist. This is admittedly an extreme case of imperfect competition. As discussed in Section 5, qualitative insights would be similar in the more general (though less tractable) case of an oligopoly.

\subsection{Social optimum}

Let $\gamma \geq 0$ be the constant marginal external cost of energy use. External costs may arise from environmental pollution or energy security concerns. A benevolent social planner would maximise total surplus TS, defined as the difference between the gross consumer surplus and the three types of costs: the production cost, the energy cost and the external cost.

$$
\begin{aligned}
\underset{\phi_{h}, \phi_{l}}{\operatorname{Maximise}} T S= & n_{h}\left(\beta_{h}\left(v-(g+\gamma) \phi_{h}\right)-c\left(\phi_{h}\right)\right) \\
& +n_{l}\left(\beta_{l}\left(v-(g+\gamma) \phi_{l}\right)-c\left(\phi_{l}\right)\right)
\end{aligned}
$$

The first-order conditions for total surplus maximisation are (equilibrium outcomes are denoted with superscript ${ }^{*}$ ):

$\forall i \frac{\partial T S}{\partial \phi_{i}}=0 \Leftrightarrow-c^{\prime}\left(\phi_{i}^{*}\right)=\beta_{i}(g+\gamma) \Leftrightarrow \phi_{i}^{*}=-c^{\prime-1}\left(\beta_{i}(g+\gamma)\right)$

\footnotetext{
${ }^{8}$ As discussed by Fischer, the willingness to invest $v_{i}$ and the discounted frequency of utilization $u_{i}$ could be determined endogenously through the following net utility: $v_{i}\left(u_{i}\right)-u_{i} g \phi_{j}-p_{j}$. However, thanks to the Envelope theorem, the impact of small changes in $u_{i}$ on utility would be second-order compared to those of $\phi_{j}$. As we are primarily interested here in how firms set $\phi_{j}$, we follow Fischer and keep utilization exogenous through $\beta_{i}$. For a model with endogenous frequency of utilization, see Giraudet and Houde (2014).
}

Table 2

Equilibrium notations

\begin{tabular}{lll}
\hline & Superscript & Associated equilibrium \\
\hline Market structures & $*$ & $\begin{array}{l}\text { Social optimum } \\
\text { Monopoly equilibrium } \\
\text { Competitive equilibrium with energy-use } \\
\text { externalities } \\
\text { Laissez-faire equilibrium } \\
\text { (monopoly + energy-use externalities) }\end{array}$ \\
\hline First-best policies & AA & Differentiated ad valorem subsidy \\
& PP & Differentiated per-quality subsidy \\
\hline Second-best policies & A & Uniform ad valorem subsidy \\
& P & Uniform per-quality subsidy \\
& H & Subsidy restricted to good $h$ \\
& T & Energy tax (see Appendix 1) \\
& Sinimum energy efficiency standard \\
& & (see Appendix 2) \\
\hline
\end{tabular}

The social planner would separate the two markets and allocate good $i$ to consumer $i$. Optimal energy efficiency levels would be set so that marginal production costs equate to the discounted social value of energy savings to the targeted consumer. ${ }^{9}$

If energy-use externalities are not internalised, energy efficiency levels are set at lower values (denoted with superscript $E$ ): $\forall i \phi_{i}^{E}=-c^{\prime-1}\left(\beta_{i} g\right)>\phi_{i}^{*}$.

\subsection{Monopoly}

To isolate the discrimination problem from energy-use externalities, we first suppose that the latter are internalised by the regulator through a Pigouvian tax. Consumers thus face social energy cost $g+\gamma$ and enjoy surplus $C S_{i j}^{*} \equiv \beta_{i}\left(v-(g+\gamma) \phi_{j}\right)-p_{j}$.

In Section 2.5, we will study how the two market failures interfere with one another. ${ }^{10}$

\subsubsection{Perfectly discriminating monopolist}

A perfectly discriminating monopolist would maximise the following profit function:

$\underset{\phi_{h}, \phi_{l}, p_{h}, p_{l}}{\operatorname{Maximise}} \pi=n_{h}\left(p_{h}-c\left(\phi_{h}\right)\right)+n_{l}\left(p_{l}-c\left(\phi_{h}\right)\right)$

subject to individual rationality constraints $\left(\mathrm{IR}^{\mathrm{M}}\right): C S_{i j}^{*} \geq 0$. The resulting energy efficiency levels would be similar to those set by the social planner. Moreover, prices would be set so as to extract all consumer surplus: $p_{j}=\beta_{j}\left(v-(g+\gamma) \phi_{j}\right)$.

\subsubsection{The screening problem}

More realistically, the monopolist knows the distribution of consumer types but cannot prevent consumers $h$ from buying the goods targeting consumers $l$, or cannot prevent arbitrage. A screening problem arises. If the monopolist sets prices and energy efficiency levels as above, then consumers $h$ will purchase good $l$. By doing so, consumers $h$ will enjoy a positive surplus $C S_{h l}^{*}=\left(\beta_{h}-\beta_{l}\right)\left(v-(g+\gamma) \phi_{l}^{*}\right)$, instead of zero surplus by consuming good $h$.

${ }^{9}$ Throughout, we assume that $-c^{\prime}(\Phi)<g \beta_{\text {l }}$, which guarantees separating equilibria with interior solutions. If $g \beta_{l} \leq-c^{\prime}(\Phi)<g \beta_{h}$ then in the equilibria studied hereafter $\phi_{h}$ will be interior and $\phi_{l}$ will be a corner solution. If $-c^{\prime}(\Phi) \geq g \beta_{h}$ there will be a pooling equilibrium at the corner solution.

${ }^{10}$ In fact, there are three market failures in the model: energy-use externalities, imperfect competition and imperfect information. In our unit purchase model with no extensive margin, imperfect competition alone changes surplus distribution but not Pareto-efficient allocations. It is the very interaction between imperfect competition and imperfect information that deteriorates social welfare. Therefore, in the model, we view the combination of the two as a single market failure. 


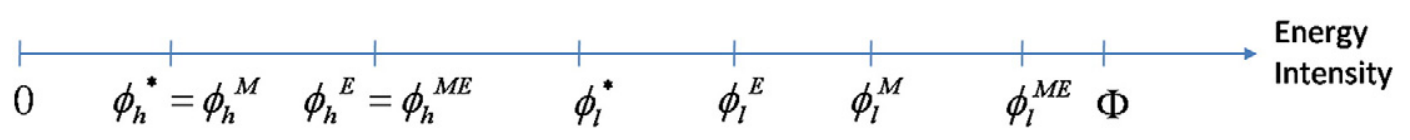

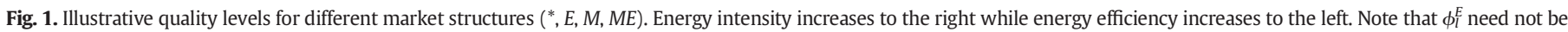
more energy-efficient than $\phi_{l}^{M}$; it depends on Condition (5). Likewise, $\phi_{h}^{M E}$ need not be more energy-efficient than $\phi_{i}^{*}$; it depends on Condition (19).

\subsubsection{Imperfectly discriminating monopolist}

As first demonstrated by Mussa and Rosen (1978), to prevent consumers $h$ from purchasing good $l$, the imperfectly discriminating monopolist does two things: reduces the price of good $h$ and cuts the quality of good $l$, as compared to their perfect discrimination levels. The latter diminishes the surplus to consumers $h$ from buying good $l$, hence allows the monopolist to make consumers $h$ indifferent to the choice between the two goods without reducing the price of good $h$ too much. The monopolist cannot deteriorate good $l$ too much, though, otherwise the loss of profit from producing a low-end good is no longer compensated by the surplus extracted from consumers $h$.

Formally, such an equilibrium requires the monopolist to endogenize Incentive Compatibility constraints (IC) in addition to IR constraints to ensure that consumers self-select the good that is targeted at them. The monopolist maximises profit subject to (superscript $M$ denotes monopoly outcomes):

$\mathrm{IR}_{l}{ }^{\mathrm{M}}: \beta_{l}\left(v-(g+\gamma) \phi_{l}\right) \geq p_{l}$

$\mathrm{IR}_{\mathrm{h}}{ }^{\mathrm{M}}: \beta_{h}\left(v-(g+\gamma) \phi_{h}\right) \geq p_{h}$

$\mathrm{IC}^{\mathrm{M}}: \beta_{l}\left(v-(g+\gamma) \phi_{l}\right)-p_{l} \geq \beta_{l}\left(v-(g+\gamma) \phi_{h}\right)-p_{h}$

$\mathrm{IC}_{\mathrm{h}}{ }^{\mathrm{M}}: \beta_{h}\left(v-(g+\gamma) \phi_{h}\right)-p_{h} \geq \beta_{h}\left(v-(g+\gamma) \phi_{l}\right)-p_{l}$.

It can be shown that only $\mathrm{IR}_{\mathrm{l}}$ and $\mathrm{IC}_{\mathrm{h}}$ constraints will bind (see Mahenc and Podesta (2012) for the proof). That is, consumer $l$ is left with no surplus and consumer $h$ is indifferent to which good he purchases.

In equilibrium, the quality of good $h$ will still be defined by Eq. (2), so that

$\phi_{h}^{*}=\phi_{h}^{M}$.

In contrast, the quality of good $l$ will be determined by the following first-order condition:

$-c^{\prime}\left(\phi_{l}^{M}\right)=(g+\gamma)\left(\beta_{l}-\frac{n_{h}}{n_{l}}\left(\beta_{h}-\beta_{l}\right)\right)$.

For $\phi_{l}^{M}$ to be interior, the right-hand side must be positive, hence:

$\frac{\beta_{l}}{\beta_{h}}>\frac{n_{h}}{n_{h}+n_{l}}=n_{h}$

The inequality $-c^{\prime}\left(\phi_{l}^{M}\right) \leq-c^{\prime}\left(\phi_{l}^{*}\right)$ leads to

$\phi_{l}^{M}>\phi_{l}^{*}$.

In other words, imperfect discrimination generates a suboptimal level of energy efficiency at the low end of the product range, even if energy-use externalities are fully internalised. This can be a rational explanation for the energy efficiency gap, that is, the apparently low levels of energy efficiency in the economy (Jaffe and Stavins, 1994).

The price of good $l$ leaves no surplus to low-end consumers:

$p_{l}^{M}=\beta_{l}\left(v-(g+\gamma) \phi_{l}^{M}\right)$.
In contrast, some surplus is left to the high-end consumers:

$p_{h}^{M}=v \beta_{l}-(g+\gamma) \beta_{h} \phi_{h}^{M}+(g+\gamma)\left(\beta_{h}-\beta_{l}\right) \phi_{l}^{M}$.

The distortions in the price of good $h$ and the quality of good $l$ interfere. The lower the quality offered to low-end consumers, the smaller the surplus left to high-end consumers:

$\mathrm{d} p_{h}^{M} / \mathrm{d} \phi_{l}^{M}=(g+\gamma)\left(\beta_{h}-\beta_{l}\right)>0$.

\subsection{Monopoly with energy-use externalities}

If, in addition to monopoly distortions, energy-use externalities are not internalised, a new equilibrium is established. Equilibrium outcomes (denoted with superscript $M E$ ) can easily be visualized by setting $\gamma=0$ in Eqs. (2) and (3). Energy efficiency is undersupplied at the high end of the product range:

$\phi_{h}^{M E}=\phi_{h}^{E}>\phi_{h}^{*}=\phi_{h}^{M}$.

The same effect occurs at the low end of the product range, where the two market failures reinforce each other:

$\phi_{l}^{M E}>\phi_{l}^{E}>\phi_{l}^{*}$ and $\phi_{l}^{M E}>\phi_{l}^{M}>\phi_{l}^{*}$.

There is ambiguity about which stand-alone market failure has the largest effect on the degradation of good $l$. Discrimination has a greater impact if and only if:

$\phi_{l}^{M}>\phi_{l}^{E} \Leftrightarrow \frac{\beta_{l}}{\beta_{h}}<n_{h}\left(1+\frac{g n_{l}}{\gamma+g n_{h}}\right)$.

Viewed intuitively, the inequality is likely to hold when $\gamma$ is small. Since the discrimination problem has no impact on the level of good $h$, the inequality is also a sufficient condition for the discrimination problem to generate a smaller deadweight loss than the externality problem.

\section{First-best, differentiated subsidies}

We now consider an institution responsible for regulating the imperfectly discriminating monopolist, subject to energy-use externalities. The monopolist and the regulator are assumed to share the same level of information. The regulator, unable to implement anti-trust regulation, seeks to move the energy efficiency pair from its laissez-faire level $\left(\phi_{h}^{M E}, \phi_{l}^{M E}\right)$ to become socially optimal $\left(\phi_{h}^{*}, \phi_{l}^{*}\right)$.

According to Tinbergen's rule, the regulator should employ two policy instruments to address the two market failures. This can be done in different ways. The regulator can combine what we shall call single instruments, that is, policies with only one instrument variable. Perhaps the most intuitive approach would be to combine a minimum quality standard equal to $\phi_{l}^{*}$ to address the discrimination problem and an energy tax equal to $\gamma$ to address the externality problem.

Alternatively, the regulator can use differentiated instruments, that is, policies that accommodate several instrument variables. In the context of the model, where energy efficiency is undersupplied, this can be achieved through differentiated subsidies. 
In this section, we compare per-quality and ad valorem subsidy designs. As in the rest of the paper, we consider a partial equilibrium framework in which subsidies are received by consumers and funded by lump-sum taxes. In this context, the results would be the same if the subsidies were received by the firm. We discuss government budget constraints in Section 5.

\subsection{Per-quality subsidies}

The regulator can offer subsidy payments that depend on the energy efficiency level of the energy-related good purchased by the consumer, as for instance in the US (Houde and Aldy, 2014) and China (Yao et al., 2014).

Such an incentive can be modelled as a two-stage game played by a principal, the regulator, and an agent, the monopolist. In the second stage of the game, the monopolist takes policy parameters as given and sets price and energy efficiency levels so as to maximise profit under the consumers' individual rationality and incentive compatibility constraints. Using backward induction, resolution of the second stage gives equilibrium outcomes as functions of the policy parameters. In the first stage of the game, the regulator sets policy parameters so as to maximise total surplus.

\subsubsection{Second stage: monopolist's response to the instruments}

Consumers receive a payment $\left(z_{i}-\phi_{i}\right) \sigma_{i}$ for purchasing good $i$, with $\sigma_{i}$ the per-quality subsidy rate. The $z_{i}$ s are arbitrary energy-intensity reference levels below which consumers receive the payment. The monopolist maximises profit subject to (equilibrium outcomes are denoted with superscript $P P$ ):

$\mathrm{IR}_{\mathrm{l}}^{\mathrm{PP}}: \beta_{l}\left(v-g \phi_{l}\right)+\left(\phi_{l}-z_{l}\right) \sigma_{l} \geq p_{l}$

$\mathrm{IR}_{\mathrm{h}}^{\mathrm{PP}}: \beta_{h}\left(v-g \phi_{h}\right)+\left(\phi_{h}-z_{h}\right) \sigma_{h} \geq p_{h}$

$\mathrm{IC}_{l}^{\mathrm{PP}}: \beta_{l}\left(v-g \phi_{l}\right)+\left(\phi_{l}-z_{l}\right) \sigma_{l}-p_{l} \geq \beta_{l}\left(v-g \phi_{h}\right)+\left(\phi_{h}-z_{h}\right) \sigma_{h}-p_{h}$

$\mathrm{IC}_{\mathrm{h}}{ }^{\mathrm{PP}}: \beta_{h}\left(v-g \phi_{h}\right)+\left(\phi_{h}-z_{h}\right) \sigma_{h}-p_{h} \geq \beta_{h}\left(v-g \phi_{l}\right)+\left(\phi_{l}-z_{l}\right) \sigma_{l}-p_{l}$.

With binding $\mathrm{IR}_{\mathrm{l}}^{\mathrm{PP}}$ and $\mathrm{IC}_{\mathrm{h}}^{\mathrm{PP}}$ constraints, equilibrium efficiency levels are determined by the following first-order conditions:

$-c^{\prime}\left(\phi_{h}^{P P}\right)=\sigma_{h}+g \beta_{h}$

$-c^{\prime}\left(\phi_{l}^{P P}\right)=g\left(\beta_{l}-\frac{n_{h}}{n_{l}}\left(\beta_{h}-\beta_{l}\right)\right)+\sigma_{l}$.

Per-quality subsidies raise both the energy efficiency $\left(\mathrm{d} \phi_{i}^{P P} /\right.$ $\left.\mathrm{d} \sigma_{i}=-1 / c^{\prime \prime}\left(\phi_{i}^{P P}\right)<0\right)$ and price $\left(\mathrm{d} p_{i}^{P P} / \mathrm{d} \sigma_{i}=g \beta_{i}>0\right)$ levels of the good they specifically target. While a subsidy on good $h$ does not change the price of good $l\left(\mathrm{~d} p_{l}^{P P} / \mathrm{d} \sigma_{h}=0\right)$, a subsidy on good $l$ reduces the price of good $h$ :

$\frac{\mathrm{d} p_{h}^{P P}}{\mathrm{~d} \sigma_{l}}=-g\left(\beta_{h}-\beta_{l}\right)<0$.

This is because with $\sigma_{l}$, good $l$ becomes more efficient and would provide consumer $h$ with a higher surplus, were this consumer to buy that good. The monopolist thus responds by lowering the price of $h$ to ensure that consumer $h$ remains indifferent to buying either good. In contrast, as $\mathrm{IC}_{1}$ does not bind, the choice of consumer $l$ is not affected by $\sigma_{h}$, so the monopolist does not need to change the price of good $l$.

\subsubsection{First stage: regulator's intervention}

The regulator seeks the subsidy rates that maximise total surplus, taking into account energy-use externalities. This leads to the same first-order conditions for both goods:

$\forall i n_{i}\left[-(g+\gamma) \beta_{i}-c^{\prime}\left(\phi_{i}^{P P}\right)\right] \frac{\mathrm{d} \phi_{i}^{P P}}{\mathrm{~d} \sigma_{i}}=0$.

Since $\mathrm{d} \phi_{i}^{P P} / \mathrm{d} \sigma_{i}<0$, both subsidies will implement the socially optimal energy efficiency levels:

$\forall i-c^{\prime}\left(\phi_{i}^{P P}\right)=(g+\gamma) \beta_{i}$

By matching the right-hand side of Eq. (9) with that of Eq. (6), we derive the optimal subsidy rate on good $h$ to correct the two market failures:

$\sigma_{h}^{P P}=\beta_{h} \gamma$

By matching the right-hand side of Eq. (9) with that of Eq. (7), we obtain the optimal subsidy rate on good $l$ :

$\sigma_{l}^{P P}=\beta_{l} \gamma+g \frac{n_{h}}{n_{l}}\left(\beta_{h}-\beta_{l}\right)$.

\subsubsection{Comments}

Subsidy rates $\sigma_{h}^{P P}$ and $\sigma_{l}^{P P}$ can be broken down into two additive components. The $\beta_{i} \gamma$ terms are the components needed to internalise the energy-use externality. The second term - zero for $\sigma_{h}^{P P}$ and $g\left(\beta_{h}-\beta_{l}\right) n_{h} / n_{l}$ for $\sigma_{l}^{P P}-$ is the one required to address the discrimination problem.

Determining which subsidy rate should be higher is not straightforward. It relies on the following condition:

$\sigma_{h}^{P P}>\sigma_{l}^{P P} \Leftrightarrow \frac{\gamma}{g}>\frac{n_{h}}{n_{l}}$

The externality must be large and/or the market share of the highend consumers must be small for the subsidy rates to increase with energy efficiency. To put this condition into perspective, in OECD countries current estimates of the implicit carbon price are typically around $10 \%$ of domestic energy price, hence $\gamma / g \approx 0.1$. In such a market environment, the market share of the high-end consumers should be no greater than $11 \%$ for the optimal subsidy regime to increase with energy efficiency.

\subsection{Ad valorem subsidies}

Instead of relating subsidy rates to the quality of goods, they may be linked to the price of those goods. This is the prevailing regime in many countries. Besides the French example mentioned in the introduction, in Germany, the KfW Bank offers price cuts of $10 \%$ for retrofitting of residential buildings if the project exceeds building code requirements by $15 \%$, and $25 \%$ if the project meets the Passivhaus standard (Rüdinger, 2013). Such an instrument is modelled here using the same principalagent framework as before.

\subsubsection{Second stage: monopolist's response to the instruments}

Let $\epsilon_{i}$ be the ad valorem subsidy rate on good $i$. $p_{i}$ denotes producer prices while $p_{i}\left(1-\epsilon_{i}\right)$ denotes consumer prices. The monopolist maximises profit subject to

$\mathrm{IR}_{l}^{\mathrm{AA}}: \beta_{l}\left(v-g \phi_{l}\right) \geq p_{l}\left(1-\epsilon_{l}\right)$

$\mathrm{IR}_{\mathrm{h}}{ }^{\mathrm{AA}}: \beta_{h}\left(v-g \phi_{h}\right) \geq p_{h}\left(1-\epsilon_{h}\right)$

$\mathrm{IC}^{\mathrm{AA}}: \beta_{l}\left(v-g \phi_{l}\right)-p_{l}\left(1-\epsilon_{l}\right) \geq \beta_{l}\left(v-g \phi_{h}\right)-p_{h}\left(1-\epsilon_{h}\right)$ 
$\mathrm{IC}_{\mathrm{h}}{ }^{\mathrm{AA}}: \beta_{h}\left(v-g \phi_{h}\right)-p_{h}\left(1-\epsilon_{h}\right) \geq \beta_{h}\left(v-g \phi_{l}\right)-p_{l}\left(1-\epsilon_{l}\right)$.

Under binding $\mathrm{IR}_{\mathrm{l}}^{\mathrm{AA}}$ and $\mathrm{IC}_{\mathrm{h}}^{\mathrm{AA}}$ constraints, profit maximisation leads to the following first-order conditions:

$-c^{\prime}\left(\phi_{h}^{A A}\right)=g \frac{\beta_{h}}{1-\epsilon_{h}}$

$-c^{\prime}\left(\phi_{l}^{A A}\right)=g\left(\frac{\beta_{l}}{1-\epsilon_{l}}-\frac{n_{h}}{n_{l}} \frac{\beta_{h}-\beta_{l}}{1-\epsilon_{h}}\right)$.

Like per-quality subsidies, ad valorem subsidies increase the energy efficiency of the good they specifically target:

$\forall i \frac{\mathrm{d} \phi_{i}^{A A}}{\mathrm{~d} \epsilon_{i}}=\frac{-g \beta_{i}}{\left(1-\epsilon_{i}\right)^{2} c^{\prime \prime}\left(\phi_{i}^{A A}\right)}<0$.

Yet, unlike per-quality subsidies, ad valorem subsidies involve some interference. The subsidy on good $h$ indeed deteriorates the quality of good $l$ :

$\frac{\mathrm{d} \phi_{l}^{A A}}{\mathrm{~d} \epsilon_{h}}=\frac{n_{h}}{n_{l}} \frac{g\left(\beta_{h}-\beta_{l}\right)}{\left(1-\epsilon_{h}\right)^{2} c^{\prime \prime}\left(\phi_{l}^{A A}\right)}>0$.

This is because, of the two channels that can be used by the monopolist to maximise profit, namely cutting $\phi_{l}$ or increasing $p_{h}$, an ad valorem subsidy makes the latter costlier. The monopolist would therefore choose the former.

Using the binding constraints, equilibrium prices before subsidies are:

$p_{l}^{A A}=\frac{\beta_{l}\left(v-g \phi_{l}^{A A}\right)}{1-\epsilon_{l}}$

$p_{h}^{A A}=\frac{g \beta_{h}\left(\phi_{l}^{A A}-\phi_{h}^{A A}\right)-\beta_{l}\left(v-g \phi_{l}^{A A}\right)}{1-\epsilon_{h}}$.

The effect of ad valorem subsidies on the prices of the durable goods is more subtle than that of per-quality subsidies. The two subsidies have opposing effects on the price of good $l$, which reflects their opposing effects on the quality of that good:

$\frac{\mathrm{d} p_{l}^{A A}}{\mathrm{~d} \epsilon_{l}}=\frac{1}{1-\epsilon_{l}}\left(p_{l}^{A A}-g \beta_{l} \frac{\mathrm{d} \phi_{l}^{A A}}{\mathrm{~d} \epsilon_{l}}\right)>0$

$\frac{\mathrm{d} p_{l}^{A A}}{\mathrm{~d} \epsilon_{h}}=\frac{-g \beta_{l}}{1-\epsilon_{h}} \frac{\mathrm{d} \phi_{l}^{A A}}{\mathrm{~d} \epsilon_{h}}<0$

The price of good $h$ increases with $\epsilon_{h}$ and decreases with $\epsilon_{l}$ :

$$
\begin{gathered}
\frac{\mathrm{d} p_{h}^{A A}}{\mathrm{~d} \epsilon_{h}}=\frac{1}{1-\epsilon_{h}}\left(p_{h}^{A A}-g \beta_{h} \frac{\mathrm{d} \phi_{h}^{A A}}{\mathrm{~d} \epsilon_{h}}+g\left(\beta_{h}+\beta_{l}\right) \frac{\mathrm{d} \phi_{l}^{A A}}{\mathrm{~d} \epsilon_{h}}\right)>0 \\
\frac{\mathrm{d} p_{h}^{A A}}{\mathrm{~d} \epsilon_{l}}=\frac{g\left(\beta_{h}+\beta_{l}\right)}{1-\epsilon_{h}} \frac{\mathrm{d} \phi_{l}^{A A}}{\mathrm{~d} \epsilon_{l}}<0 .
\end{gathered}
$$

\subsubsection{First stage: regulator's intervention}

The regulator seeks the subsidy levels that maximise total surplus, taking into account energy-use externalities. The first-order conditions for maximisation are:

$n_{h}\left[-(g+\gamma) \beta_{h}-c^{\prime}\left(\phi_{h}^{A A}\right)\right] \frac{\mathrm{d} \phi_{h}^{A A}}{\mathrm{~d} \epsilon_{h}}+n_{l}\left[-(g+\gamma) \beta_{l}-c^{\prime}\left(\phi_{l}^{A A}\right)\right] \frac{\mathrm{d} \phi_{l}^{A A}}{\mathrm{~d} \epsilon_{h}}=0$ $n_{l}\left[-(g+\gamma) \beta_{l}-c^{\prime}\left(\phi_{l}^{A A}\right)\right] \frac{\mathrm{d} \phi_{l}^{A A}}{\mathrm{~d} \epsilon_{l}}=0$

Since $\mathrm{d} \phi_{l}^{A A} / \mathrm{d} \epsilon_{l}>0$, Eq. (15) simplifies to:

$-c^{\prime}\left(\phi_{l}^{A A}\right)=(g+\gamma) \beta_{l}$.

This implies that the efficiency of good $l$ will be set at its optimal level. This result, implemented in Eq. (14) and combined with the fact that $\mathrm{d} \phi_{h}^{A A} / \mathrm{d} \epsilon_{h}<0$ implies that good $h$ will also be set at its optimal level:

$-c^{\prime}\left(\phi_{h}^{A A}\right)=(g+\gamma) \beta_{h}$.

By matching the right-hand side of Eq. (17) with that of Eq. (10), we derive the optimal subsidy rate on good $h$ to correct the two market failures:

$\epsilon_{h}^{A A}=\frac{\gamma}{g+\gamma}$

Using this and matching the right-hand side of Eq. (16) with that of Eq. (11), we derive the optimal subsidy rate on good $l$ :

$\epsilon_{l}^{A A}=\frac{n_{h}\left(\beta_{h}-\beta_{l}\right)+\frac{\gamma}{g+\gamma} n_{l} \beta_{l}}{n_{h}\left(\beta_{h}-\beta_{l}\right)+n_{l} \beta_{l}}$.

\subsubsection{Comments}

Ad valorem subsidies differ from per-quality subsidies in two ways. First, they cannot be systematically broken down into two additive components meant to specifically address one market failure. If discrimination were the only market failure to address $(\gamma=0)$, the subsidy rate would be nil on good $h\left(\epsilon_{h}^{M}=0\right)$ and equal to $\epsilon_{l}^{M}=n_{h}\left(\beta_{h}-\beta_{l}\right) /$ $\left[n_{h}\left(\beta_{h}-\beta_{l}\right)+n_{l} \beta_{l}\right]$ on good $l .{ }^{11}$ Reciprocally, if energy-use externalities were the only market failure to internalise, energy efficiency levels would be set so that equilibrium levels with the subsidy (defined by $\left.-c^{\prime}\left(\phi_{i}\right)=g \beta_{i} /\left(1-\epsilon_{i}\right)\right)$ matched the socially optimal levels (defined by $\left.-c^{\prime}\left(\phi_{i}\right)=(g+\gamma) \beta_{i}\right)$. Hence, both goods would need to be subsidised at the same uniform rate $\epsilon^{E}=\gamma /(\gamma+g)$. With the orders of magnitude discussed in Section 3.1.3, this rate is typically equal to $9 \%$.

With these definitions, $\epsilon_{h}^{A A}=\epsilon^{E}+\epsilon_{h}^{M}$ and:

$\epsilon_{l}^{A A}=\epsilon^{E}+\epsilon_{l}^{M}-\epsilon_{l}^{M} \epsilon^{E}=\epsilon^{E}+\epsilon_{l}^{M}\left(1-\epsilon^{E}\right)$.

In other words, if the two market failures are to be jointly corrected, the subsidy rates specifically needed for each market failure are additive on good $h$ but sub-additive on good $l$.

A second difference between ad valorem and per-quality subsidies it that with the former, subsidy rates should always be higher on good $l$ than on good $h: \epsilon_{h}^{A A}<\epsilon_{l}^{A A}$. The interpretation of this result is that the efficiency of good $h$ must increase only to internalise the externality, whereas the efficiency of good $l$ must also increase to correct the distortion due to imperfect discrimination. Of course, subsidy amounts $p_{h}^{A A} \epsilon_{h}^{A A}$ need not be lower than $p_{l}^{A A} \epsilon_{l}^{A A}$. In practice, as the French and German examples illustrate, subsidy rates tend to increase with energy efficiency.

\section{Second-best, single-instrument subsidies}

In practice, Tinbergen's rule is rarely satisfied. For a variety of institutional or political reasons, there are seldom as many policy instruments

\footnotetext{
11 The intuition that the larger distortion at the bottom of the product line warrants decreasing subsidy regimes is alluded to, though not formally discussed, by Besanko et al (1988).
} 
as there are market failures to correct. ${ }^{12}$ In the context that interests us, for instance, implementing differentiated subsidy rates would open up the possibility of lobbying by dominant firms.

In this section, we therefore take a more positive view and examine how single-instrument subsidies perform in the context of two market failures. Theoretically, six types of single-instrument subsidy may be considered. Subsidy rates can uniformly target both goods, or specifically target either of the two goods. In each case, the rates can be ad valorem or per-quality.

Much of the analysis carried out in Section 3 carries over to the second-best analysis. The monopolist's responses to each of these instruments have already been analysed in the second stages of the principal-agent games. The difference in the second-best setting is that in the first stage of the games, the regulator maximises total surplus with respect to one instrument variable only.

For subsidies specifically targeting the low-end good (either ad valorem or per-quality) and per-quality subsidies targeting the highend good, the analysis directly derives from Section 3. It may be recalled from the second stages of the games that these subsidies do not interfere with the good they do not target. Therefore, in a second-best setting, the best that the regulator can do is to set their rates at their socially optimal level.

More analysis is needed for uniform subsidies (either ad valorem or per-quality) and ad valorem subsidies on the high-end good: these are the subject of the present section.

\subsection{Uniform subsidies}

\subsubsection{Ad valorem regime}

In France, home energy retrofits benefit from a reduced rate of value-added tax (5.5\% against a normal rate of 10\%). Various technologies of different energy efficiency levels are all equally eligible.

The monopolist's response to such a uniform ad valorem subsidy rate is directly given by Eq. (10) and (11), with $\epsilon_{h}=\epsilon_{l} \equiv \epsilon$. The comparative statics of equilibrium efficiencies is (superscript $A$ denotes equilibrium outcomes):

$$
\begin{aligned}
& \frac{\mathrm{d} \phi_{h}^{A}}{\mathrm{~d} \epsilon}=\frac{-g \beta_{h}}{c^{\prime \prime}\left(\phi_{h}^{A}\right)(1-\epsilon)^{2}}<0 \\
& \frac{\mathrm{d} \phi_{l}^{A}}{\mathrm{~d} \epsilon}=\frac{-g}{c^{\prime \prime}\left(\phi_{l}^{A}\right)(1-\epsilon)^{2}}\left(\beta_{l}-\frac{n_{h}}{n_{l}}\left(\beta_{h}-\beta_{l}\right)\right)<0 .
\end{aligned}
$$

The comparative statics of price established in 3.2.1 suggest that the effect of a uniform ad valorem subsidy on product prices will be ambiguous.

In the first stage of the game, the regulator solves Eq. (14) with $\epsilon_{h} \equiv \epsilon$. Identifying the $c^{\prime}\left(\phi_{i}\right)$ in the resulting first-order conditions with the right-hand sides in Eqs. (10) and (11), we end up with the following equality ( $A$ denotes equilibrium outcomes):

$$
\epsilon^{A}=\epsilon^{E}+\left(1-\epsilon^{E}\right) \frac{n_{h}\left(\beta_{h}-\beta_{l}\right) \mathrm{d} \phi_{l}^{A} / \mathrm{d} \epsilon}{n_{h} \beta_{h} \mathrm{~d} \phi_{h}^{A} / \mathrm{d} \epsilon+n_{l} \beta_{l} \mathrm{~d} \phi_{l}^{A} / \mathrm{d} \epsilon} .
$$

The second-best uniform rate is higher than that needed to specifically internalise energy-use externalities. As a result, the quality of the high-end good will be higher than the socially optimal one.

\footnotetext{
12 To quote Tinbergen himself, "Economists or economic politicians holding the opinion that there is such a one-by-one correspondence between targets and instruments evidently assume a very special structure." (Tinbergen, 1952, note 1, p. 31).
}

How the uniform subsidy rate compares to $\epsilon_{l}^{A A}$ depends on how the fraction in the right-hand side of the above equality compares to $\epsilon_{l}^{M}$. The comparison leads to the following equivalence:

$$
\epsilon^{A}<\epsilon_{l}^{A A} \Leftrightarrow 1-\frac{\beta_{l}}{\beta_{h}}<\frac{\mathrm{d} \phi_{h}^{A} / \mathrm{d} \epsilon}{\mathrm{d} \phi_{l}^{A} / \mathrm{d} \epsilon}=\frac{\beta_{h}}{\beta_{l}-\left(\beta_{h}-\beta_{l}\right) n_{h} / n_{l}} \frac{c^{\prime \prime}\left(\phi_{l}^{A}\right)}{C^{\prime \prime}\left(\phi_{h}^{A}\right)} .
$$

The conditions under which the inequality holds are ambiguous. With a quadratic cost function, $c^{\prime \prime}\left(\phi_{h}^{A}\right) / c^{\prime \prime}\left(\phi_{h}^{A}\right)$ would be equal to 1 . The right-hand side of the inequality would be greater than 1 and, since the left-hand side is lower than 1, the inequality would always hold. The uniform subsidy rate would be lower than the first-best rate on the low-end good. As a result, the quality of the low-end good would be lower than the socially optimal one.

\subsubsection{Per-quality regime}

The monopolist's response to such a subsidy is the same as that described in Section 3.1.1. Using the same reasoning as before, the regulator will set the uniform per-quality subsidy at the following level ( $P$ denotes equilibrium outcomes):

$$
\sigma^{P}=\frac{\sigma_{h}^{P P}}{1+\frac{n_{l}}{n_{h}} \frac{\mathrm{d} \phi_{l}^{P} / \mathrm{d} \sigma}{\mathrm{d} \phi_{h}^{P} / \mathrm{d} \sigma}}+\frac{\sigma_{l}^{P P}}{1+\frac{n_{h}}{n_{l}} \frac{\mathrm{d} \phi_{h}^{P} / \mathrm{d} \sigma}{\mathrm{d} \phi_{l}^{P} / \mathrm{d} \sigma}}<\sigma_{h}^{P P}+\sigma_{l}^{P P} .
$$

The payment to consumers will be lower than the sum of the two differentiated per-quality subsidies $\left(\sigma_{h}^{P P}+\sigma_{l}^{P P}\right)$.

\subsection{Subsidies restricted to the high-end good}

\subsubsection{Ad valorem regime}

Recent changes in the French tax credit programme resemble such an instrument. Only the best available technologies are incentivised (e.g. condensing boilers, etc.) with a $30 \%$ price reduction.

It may be recalled from Section 3.2.1 that an ad valorem subsidy on good $h$ deteriorates the quality of good $l\left(\mathrm{~d} \phi_{l}^{H} / \mathrm{d} \epsilon_{h}>0\right.$, (where superscript $H$ here denotes equilibrium outcomes). Therefore, in this case, the quality of good $h$ in equilibrium will be below its socially optimal level $\phi_{h}^{*}$ and the quality of good $l$ will be even below its laissez-faire level $\phi_{l}^{M E}$.

In the first stage of the game the regulator sets the ad valorem incentive at the following rate:

$$
\epsilon_{h}^{H}=\frac{\gamma n_{h} \beta_{h} \mathrm{~d} \phi_{h}^{H} / d \epsilon_{h}+\left(\gamma n_{l} \beta_{l}+g n_{h}\left(\beta_{h}-\beta_{l}\right)\right) \mathrm{d} \phi_{l}^{H} / d \epsilon_{h}}{(\gamma+g) n_{h} \beta_{h} \mathrm{~d} \phi_{h}^{H} / d \epsilon_{h}+\left(\gamma n_{l} \beta_{l}+g n_{h}\left(\beta_{h}-\beta_{l}\right)\right) \mathrm{d} \phi_{l}^{H} / d \epsilon_{h}} .
$$

Since the $\mathrm{d} \phi_{i}^{H} / \mathrm{d} \epsilon_{h}$ components have opposite signs, the sign of this expression is ambiguous. If it is negative, the second-best incentive on good $h$ shifts from a subsidy to a tax. This occurs if, and only if, the numerator and the denominator have opposite signs. Since the denominator is smaller than the numerator, this condition is equivalent to having a positive numerator and a negative denominator. Therefore:

$\epsilon_{h}^{H}<0 \Leftrightarrow 0<\gamma n_{h} \beta_{h} \frac{\mathrm{d} \phi_{h}^{H}}{\mathrm{~d} \epsilon_{h}}+\left(\gamma n_{l} \beta_{l}+g n_{h}\left(\beta_{h}-\beta_{l}\right)\right) \frac{\mathrm{d} \phi_{l}^{H}}{\mathrm{~d} \epsilon_{h}}<-g n_{h} \beta_{h} \frac{\mathrm{d} \phi_{h}^{H}}{\mathrm{~d} \epsilon_{h}}$.

This condition is likely to hold if $\gamma$ is small enough and type $l$ consumers dominate the market. To verify this, assume that $\gamma$ is negligible. The condition reduces to:

$0<1-\frac{\beta_{l}}{\beta_{h}}<-\frac{\mathrm{d} \phi_{h}^{H} / \mathrm{d} \epsilon_{h}}{\mathrm{~d} \phi_{l}^{H} / \mathrm{d} \epsilon_{h}}=\frac{n_{l}}{n_{h}} \frac{\beta_{h}}{\beta_{h}-\beta_{l}} \frac{c^{\prime \prime}\left(\phi_{l}^{H}\right)}{C^{\prime \prime}\left(\phi_{h}^{H}\right)}$. 
We know from Eqs. (10) and (11) that $\phi_{l}^{H}>\phi_{h}^{H}$, but without further assumptions on $c^{\prime \prime \prime}(\cdot)$, we do not know how $c^{\prime \prime}\left(\phi_{l}^{H}\right) / c^{\prime \prime}\left(\phi_{h}^{H}\right)$ compares to 1 . Still, if $n_{l}$ is greater than $n_{h}$ to a sufficiently large extent, the right-hand side of the inequality will be greater than 1 and the inequality will be satisfied.

This outcome can be rationalised as follows. If the externality is very small, then the high-end good is very close to its socially optimal level, while the low-end good is far from its socially optimal level. Therefore, the tax has a first-order effect on good $l$ but only a second-order effect on good $h$. In other words, with the tax, the marginal welfare gain from improving good $l$ is greater than the marginal welfare loss from deteriorating good $h$. The fact that $n_{l}$ is greater than $n_{h}$ only amplifies this effect.

It should, however, be borne in mind that having a small $\gamma$ and a large $n_{l}$ is neither a necessary nor a sufficient condition for the optimal incentive to be a tax. Clearer conditions can be derived using a more restrictive quadratic cost assumption. Hence, the second derivative of cost is constant. The last fraction drops from the inequality, which becomes:

$\left[\left(1-\frac{\beta_{l}}{\beta_{h}}\right)^{2}+\frac{\beta_{l}}{\beta_{h}}\right]<\frac{g}{\gamma} \frac{n_{h}}{n_{l}}\left(1-\frac{\beta_{l}}{\beta_{h}}\right)^{2}<\left[\left(1-\frac{\beta_{l}}{\beta_{h}}\right)^{2}+\frac{\beta_{l}}{\beta_{h}}\right]+\frac{g}{\gamma}$.

The interior condition $\beta_{l} / \beta_{h} \geq n_{h}$ implies that $n_{l} \geq n_{h}\left(1-\beta_{l} / \beta_{h}\right)^{2}$, hence the right-hand inequality. Therefore, with quadratic costs, the left-hand inequality above is sufficient for the incentive to be a tax.

\subsubsection{Per-quality regime}

In France, a $1350 €$ subsidy on energy efficiency investment was introduced in 2014 for middle- and low-income households undergoing home energy retrofit works. The programme has similar eligibility requirements as the most recent version of the tax credit programme. It can be seen as a per-quality subsidy on the most energy efficient goods.

With a per-quality subsidy on good $h$, the quality of good $h$ will be socially optimal $\left(\phi_{h}^{*}\right)$ and the quality of good $l$ will be unchanged $\left(\phi_{l}^{M E}\right)$. This instrument therefore strictly dominates the second-best ad valorem subsidy on good $h$, which brings both goods to lower quality levels. Yet if the ad valorem subsidy turns out to be a tax (under Condition (22)), the comparison with the per-quality subsidy is no longer straightforward. According to the comparative statics of quality levels with respect to $\epsilon_{h}$ (Eqs. (12) and (13)), the tax will push the quality of good $h$ away from its socially optimal level (which is worse than the per-quality equivalent) but bring the quality of good $l$ closer to its socially optimal level (which is better than the per-quality equivalent).

\section{Discussion}

In this section, we re-examine how the main assumptions of our model affect the results. It should first be recalled that we model only two types of consumers and two goods. In general, the finding of no distortion at the top of the product range is robust to extensions to more than two consumers or a continuum thereof (Mussa and Rosen, 1978).

We focus on the intensive margin of investment and consider energy efficiency as the only dimension of quality. These assumptions are well suited to product replacement within a capacity segment. This is most relevant to operations on heating systems, which we used as our leading example. Introducing other dimensions of quality would reinforce the superiority of per-quality subsidies over ad valorem ones, when only good $h$ is subsidised. Indeed, ad valorem subsidies would reduce the marginal cost of increasing the qualities unrelated to energy efficiency. This would not occur with per-quality subsidies, which can be targeted at only one dimension of quality (energy efficiency). As a result, ad valorem subsidies on good $h$ would generate an oversupply of these other dimensions of quality.

A strong assumption of the model is the existence of a monopoly. In the more general case of an oligopoly where firms specialise in one quality, all firms would contribute to market segmentation. As a result, the quality of the high-end good would also be distorted - in fact it would be too high (Cremer and Thisse, 1994). This would partly compensate any undersupply of quality induced by energy-use externalities, while at the low-end of the product range, the two market failures reinforce each other, exactly like the monopoly situation. At some point, if the externality is low enough, the quality of the high-end good under the two conditions for market failure may be above its socially optimal level, thus warranting a tax on the low-end good. More generally, an oligopoly would render less restrictive the conditions for the optimal incentive on the high-end good to be a tax.

We have ignored the opportunity cost of public funds. If the Government faced budget constraints, the efficiency of those interventions involving large transfers would be lower. This would narrow the welfare gap between single-instrument subsidies and differentiated subsidies, which involve higher amounts. Moreover, the public cost of perquality subsidies can be limited by setting a relatively high reference level $z_{i}$. It can even be nullified or become negative by taxing the goods whose efficiency is below the reference level - as in the feebate system currently implemented in the automobile sector in various countries. ${ }^{13}$ This policy variable is not available with ad valorem subsidies. Hence, introducing an opportunity cost of public funds would also reinforce the superiority of per-quality subsidies over ad valorem ones.

Lastly, an important result of our analysis is the higher first-best ad valorem subsidy rate on the low-end good, as compared to the highend good. This result is very specific to the market failures taken into account. Technology spillovers would be another relevant market failure to consider. It is plausible to suppose that more energy-efficient products are less mature than less energy-efficient ones, hence generate greater spillovers. In this perspective, the subsidies needed to internalise technology spillovers would be higher on high-end goods, thus countervailing the effects studied in the analysis.

\section{Conclusion}

Energy efficiency markets are commonly subject to both energy-use externalities and price-quality discrimination. They are also the domain of various types of subsidies, the properties of which have been little studied. To address this knowledge gap, we have used and extended Fischer (2005)'s model to examine a variety of first-best and secondbest energy efficiency subsidies in the presence of the two market failures. We have considered two types of consumer (high and low), a multiproduct monopolist whose price discrimination is imperfect and two levels of energy efficiency which are positively correlated with quality.

From a normative perspective, the two levels of energy efficiency are undersupplied in laissez-faire. This so-called energy efficiency gap can be addressed with energy efficiency subsidies, the rate of which is differentiated across energy efficiency levels. Subsidy regimes can be either per-quality or ad valorem, with different consequences. We find that with ad valorem subsidies, the rate on the more energy-efficient goods interferes with the provision of less energy-efficient goods. The rates should always decrease with energy efficiency, a result seemingly at odds with actual practice. With per-quality subsidies, there are no such interferences and the rates can increase if the marginal external cost of energy use is large enough relative to the market share of lowtype consumers.

From a positive perspective, for a variety of institutional and political reasons, single instruments are more likely to be implemented. We find

\footnotetext{
13 The feebate system, implemented e.g. in France, Canada, the Netherlands and Norway, combines taxes and subsidies, the amount of which depends on the energy efficiency level of the car purchased, regardless of its price (d'Haultfoeuille et al., 2013).
} 
that a uniform ad valorem subsidy should be set above the subsidy that would be needed to specifically internalise energy-use externalities. Lastly, if, as is often observed in practice, only the high-end good is to be incentivised, a per-quality regime should be preferred to an ad valorem one. An ad valorem tax may even be preferred to an ad valorem subsidy if the externality is small enough and low-end consumers dominate the market.

\section{Acknowledgements}

We thank the two anonymous referees and seminar participants at INRA, CIRED, and Paris Environmental and Energy Economics Seminar for helpful comments.

\section{Appendix 1. Energy tax}

Most European countries, Japan and a few other countries have implemented significant fuel taxes in the transport sector. These taxes were found to efficiently restrain fuel demand (Sterner, 2007).

Energy taxes here are assumed to be funded by lump-sum subsidies.

Second stage: monopolist's response

A tax on energy at rate $t$ would lead to the following first-order conditions (superscript $T$ denotes equilibrium outcomes):

$-c^{\prime}\left(\phi_{h}^{T}\right)=(g+t) \beta_{h}$

$-c^{\prime}\left(\phi_{l}^{T}\right)=(g+t)\left(\beta_{l}-\frac{n_{h}}{n_{l}}\left(\beta_{h}-\beta_{l}\right)\right)$.

The tax would increase the energy efficiency of the two goods:

$\frac{\mathrm{d} \phi_{h}^{T}}{\mathrm{~d} t}=\frac{-\beta_{h}}{C^{\prime \prime}\left(\phi_{h}^{T}\right)}<0$

$\frac{\mathrm{d} \phi_{l}^{T}}{\mathrm{~d} t}=\frac{-1}{c^{\prime \prime}\left(\phi_{l}^{T}\right)}\left(\beta_{l}-\frac{n_{h}}{n_{l}}\left(\beta_{h}-\beta_{l}\right)\right)<0$.

The effect of the tax on the price of good $l$ is ambiguous. Recall that $p_{l}^{T}=\beta_{l}\left(v-(g+t) \phi_{l}^{T}(t)\right)$. Differentiating, we obtain:

$\frac{\mathrm{d} p_{l}^{T}}{\mathrm{~d} t}=-\beta_{l} \phi_{l}^{T}\left(1+\mu_{l}\right)$ with $\mu_{l}=\frac{\mathrm{d} \phi_{l}^{T}}{\mathrm{~d} t} \frac{t}{\phi_{l}^{T}}$

Variable $\mu_{l}$ is the elasticity of the supply of energy efficiency with respect to the price of energy. If $-1<\mu_{l}<0$, a "normal" rebound effect occurs. If $\mu_{l} \geq 0$, a "backfire" rebound effect occurs. Recall that $\mathrm{d} \phi_{l}^{T} / \mathrm{d} t$ is negative, hence so is $\mu_{l}$. Therefore, $\mathrm{d} \phi_{l}^{T} / \mathrm{d} t$ is negative if there is a "normal" rebound effect and positive if there is no rebound effect $\left(\mu_{l} \leq-1\right)$.

The price of good $h$ will vary with even more ambiguity. Recall that

$p_{h}^{T}=p_{l}^{T}+\beta_{h}(g+t)\left(\phi_{l}^{T}(t)-\phi_{h}^{T}(t)\right)$.

Differentiating and using the same elasticity formulas as before, we obtain:

$\frac{\mathrm{d} p_{h}^{T}}{\mathrm{~d} t}=-\left(\beta_{h}-\beta_{l}\right) \phi_{l}^{T}\left(1+\mu_{l}\right)-\beta_{h} \phi_{h}^{T}\left(1+\mu_{h}\right)$.
First stage: regulator's intervention

The optimal tax rate to address the two market failures is the one that maximises social welfare, including energy-use externalities. This leads to the following first-order condition:

$n_{h}\left[-(g+\gamma) \beta_{h}-c^{\prime}\left(\phi_{h}^{T}\right)\right] \frac{\mathrm{d} \phi_{h}^{T}}{\mathrm{~d} t}+n_{l}\left[-(g+\gamma) \beta_{l}-c^{\prime}\left(\phi_{l}^{T}\right)\right] \frac{\mathrm{d} \phi_{l}^{T}}{\mathrm{~d} t}=0$.

Identifying the $c^{\prime}\left(\phi_{i}^{T}\right)$ with the right-hand sides in Eqs. (20) and (21), we end up with the following equality:

$t=\gamma+\frac{(g+\gamma) n_{h}\left(\beta_{h}-\beta_{l}\right) \mathrm{d} \phi_{l}^{T} / \mathrm{d} t}{n_{h} \beta_{h} \mathrm{~d} \phi_{h}^{T} / \mathrm{d} t+\left(n_{l} \beta_{l}-n_{h}\left(\beta_{h}-\beta_{l}\right)\right) \mathrm{d} \phi_{l}^{T} / \mathrm{d} t}>\gamma$.

Unless the two consumers are identical $\left(\beta_{h}=\beta_{l}\right)$, the optimal tax rate is greater than $\gamma$. If it were equal to $\gamma$, external costs would be internalised but there would still remain some deadweight loss from price-quality discrimination. Further energy taxation could reduce the deadweight loss on the quality of good $l$, to the point where the marginal welfare gains would be offset by the marginal welfare loss of an inefficiently high quality of good $h$.

This result contrasts with the classical one found in the environmental economics literature which says that under conditions of imperfect competition, the second-best tax rate needed to compensate the oversupply of a polluting good should be smaller than the Pigouvian rate, so as to balance the effect of market power on output contraction (Baumol, 1988). The difference comes from the fact that energy efficiency can be seen as a depolluting technology. In this context, instead of being mutually compensating, the two market failures are mutually reinforcing. They both contribute to an undersupply of the depolluting technology (Mahenc and Podesta, 2012).

Lastly, note that this result would be different in the case of an oligopoly, where market power also distorts quality at the top of the range (Lombardini-Riipinen, 2005).

\section{Appendix 2. Minimum energy efficiency standard}

Most European countries and some US states implemented minimum quality standards for new buildings after the oil shocks of the 1970s, and have since strengthened them. Now such standards exist in all developed countries and in many developing countries. The main types of appliances, as well as electric motors and lighting equipment, are also covered by energy efficiency standards in most of the developed and transition countries.

Let us consider the effect of a standard (denoted $S$ ) on each good $i$, independently of the other good. The deadweight loss of a standard $\phi^{S}$ on good $I$ is:

$D W L_{i}=n_{i}\left[(g+\gamma) \beta_{i}\left(\phi^{S}-\phi_{i}^{*}\right)+c\left(\phi^{S}\right)-c\left(\phi_{i}^{*}\right)\right]$.

It varies with $\phi^{S}$ in an ambiguous manner:

$\frac{\mathrm{d} D W L_{i}}{\mathrm{~d} \phi^{S}}=n_{i}\left[(g+\gamma) \beta_{i}+c^{\prime}\left(\phi^{S}\right)\right]\left\{\begin{array}{c}<0 \text { if } \phi_{i}^{*}<\phi^{S} \leq \Phi \\ =0 \text { if } \phi^{S}=\phi_{i}^{*} \\ >0 \text { if } 0 \leq \phi^{S}<\phi_{i}^{*}\end{array}\right.$

That is, tightening the standard is welfare-improving, up to the point where the socially optimal value of the good is reached. Beyond that point, further strengthening of the standard is socially detrimental. The question of interest is now: should the standard act upon the efficiency of both goods (pooling standard) or that of good $l$ only (separating standard)? 


\section{A necessary and sufficient condition for a pooling standard}

An optimal pooling standard would minimise the sum of the deadweight losses on each of the two goods. This leads to the following first-order condition:

$-c^{\prime}\left(\phi^{S}\right)=\left(n_{h} \beta_{h}+n_{l} \beta_{l}\right)(g+\gamma)$.

The pooling standard would be optimal to a consumer of average type $n_{h} \beta_{h}+n_{l} \beta_{l}$. To be effective, such a standard should be more stringent than the monopolist's supply of good $h: \phi^{S} \leq \phi_{h}^{M E}$. This is true if, and only if, $c^{\prime-1}\left(-(g+\gamma)\left(n_{h} \beta_{h}+n_{l} \beta_{l}\right)\right) \leq c^{\prime-1}\left(-g \beta_{h}\right)$, that is:

$\frac{\beta_{h}}{n_{h} \beta_{h}+n_{l} \beta_{l}} \leq 1+\frac{\gamma}{g}$

\section{A sufficient condition for a pooling standard}

If the externality is so large that $\phi_{h}^{M E} \geq \phi_{l}^{*}$ then the standard, at least equal to $\phi_{l}^{*}$, is necessarily more stringent than $\phi_{h}^{M E} \geq \phi_{l}^{*}$. This occurs when $c^{\prime-1}\left(-(g+\gamma) \beta_{l}\right) \leq c^{\prime-1}\left(-g \beta_{h}\right)$, which leads to the sufficient condition for a pooling standard:

$\frac{\beta_{h}}{\beta_{l}} \leq 1+\frac{\gamma}{g}$

Obviously, this condition implies Condition (19).

\section{Separating standard}

If Condition (19) is not satisfied, $\phi^{S}>\phi_{h}^{M E}$. It is not optimal for the monopolist to supply only one good with efficiency $\phi^{S}$. The monopolist could increase the profit earned from consumers $h$ by extending its product range to include $\phi_{h}^{M E}$. With this new constraint, the only way to minimise the total deadweight loss is to eliminate the deadweight loss from good $l$. From Eq. (18), this can only be done by setting the standard at $\phi_{l}^{*}$.

\section{References}

Allcott, H., Greenstone, M., 2012. Is there an energy efficiency gap? J. Econ. Perspect. 26 (1), 3-28.

Bansal, S., 2008. Choice and design of regulatory instruments in the presence of green consumers. Resour. Energy Econ. 30 (3), 345-368.

Baumol, W.J., 1988. The Theory of Environmental Policy. Cambridge University Press, Cambridge.

Besanko, D., Donnenfeld, S., White, L.J., 1988. The multiproduct firm, quality choice, and regulation. J. Ind. Econ. 36 (4), 411-429.

Boomhower, J., Davis, L.W., 2014. A credible approach for measuring inframarginal participation in energy efficiency programs. J. Public Econ. 113, 67-79.
Carbonnier, C., 2008. Différence des ajustements de prix à des hausses ou baisses des taux de la TVA: un examen empirique à partir des réformes françaises de 1995 et 2000. Economie et Statistique. 413(1) pp. 3-20.

Cohen, F., Glachant, M., Söderberg, M., 2015. The impact of energy prices on energy efficiency: evidence from the UK refrigerator market. GRI working paper No.179.

Cremer, H., Thisse, J.-F., 1994. Commodity taxation in a differentiated oligopoly. Int. Econ. Rev. 35 (3), 613-633.

D'Haultfoeuille, X., Durrmeyer, I., Février, P., 2013. The effect of public policies on consumers' preferences: lessons from the French automobile market. SFB/TR 15 Discussion Paper.

Conseil de la Concurrence, 2006. Décision no. 06-D-03 bis du 9 Mars 2006 Relative à des Pratiques Mises en Euvre Dans le Secteur des Appareils de Chauffage, Sanitaires, Plomberie, Climatisation.

Fischer, C., 2005. On the importance of the supply side in demand-side management. Energy Econ. 27 (1), 165-180.

Fischer, C., 2010. Imperfect competition, consumer behavior, and the provision of fuel efficiency in light-duty vehicles. RFF Discussion Paper 10-60.

Gillingham, K., Newell, R.G., Palmer, K., 2009. Energy efficiency economics and policy. Ann. Rev. Resour. Econ. 1 (1), 597-620.

Giraudet, L.G., Houde, S., 2014. Double moral hazard and the energy efficiency gap. E2e working paper 009.

Giraudet, L.-G., Quirion, P., 2008. Efficiency and distributional impacts of tradable white certificates compared to taxes, subsidies and regulations. Revue d'économie politique. Vol. 118(6) pp. 885-914.

Grösche, P., Vance, C., 2009. Willingness to pay for energy conservation and free-ridership on subsidization: evidence from Germany. Energy J. 30 (2), 135-153.

Hassett, K.A., Metcalf, G.E., 1995. Energy tax credits and residential conservation investment: evidence from panel data. J. Public Econ. 57 (2), 201-217.

Houde, S., 2013. Bunching with the stars: how firms respond to environmental Certification. Working Paper. Univesity of Maryland.

Houde, S., Aldy, J.E., 2014. Belt and suspenders and more: the incremental impact of energy efficiency subsidies in the presence of existing policy instruments. Harvard Environmental Economics Program Discussion Paper 14-59.

Jaffe, A.B., Stavins, R.N., 1994. The energy-efficiency gap: what does it mean? Energy Policy 22 (10), 804-810.

Keen, M., 1998. The balance between specific and ad valorem taxation. Fisc. Stud. 19 (1), 1-37.

Lombardini-Riipinen, C., 2005. Optimal tax policy under environmental quality competition. Environ. Resour. Econ. 32 (3), 317-336.

Mahenc, P., Podesta, M., 2012. The monopolist is not the best environmentalist's best friend: an example. Econ. Lett. 115 (3), 379-382.

McKinsey, Company, 2009. Pathways to a Low Carbon Economy: Version 2 of the Global Greenhouse Gas Abatement Cost Curve.

Mussa, M., Rosen, S., 1978. Monopoly and product quality. J. Econ. Theory 18 (2), 301-317.

Nauleau, M.-L., 2014. Free-riding on tax credits for home insulation in France: an econometric assessment using panel data. Energy Econ. 46, 78-92.

Plourde, C., Bardis, V., 1999. Fuel economy standards in a model of automobile quality. Energy Econ. 21 (4), 309-319.

Rüdinger, A., 2013. La rénovation thermique des bâtiments en France et en Allemagne: quels enseignements pour le débat sur la transition énergétique? Working Papers no. $07 / 13$ (14 pp.)

Sorrell, S., 2004. Understanding Barriers to Energy Efficiency in the Economics of Energy Efficiency Barriers to Cost-effective Investment. Edward Elgar Publishing, Cheltenham.

Spurlock, C.A., 2013. Appliance efficiency standards and price discrimination. Working Paper. Lawrence Berkeley National Laboratory.

Sterner, T., 2007. Fuel taxes: an important instrument for climate policy. Energy Policy 35 (6), 3194-3202.

Tinbergen, J., 1952. On the Theory of Economic Policy. North-Holland, Amsterdam.

Yao, X.L., Liu, Y., Xiao, Y., 2014. A quantile approach to assess the effectiveness of the subsidy policy for energy-efficient home appliances: evidence from Rizhao, China. Energy Policy 73, 512-518. 